\title{
The generalizability study as a method of assessing intra- and interobserver reliability in observational research
}

\author{
CATHRYN L. BOOTH, SANDRA K. MITCHELL, and FRANCES K. SOLIN \\ University of Washington, Seattle, Washington 98195
}

\begin{abstract}
Most researchers use interobserver agreement percentages to express the quality of their observational data. A better method is the generalizability study, which allows the variance in a set of scores to be partitioned among several sources, such as observers, occasions, subjects, and error. In this paper the practical application of generalizability theory is described and illustrated, using the frequency and duration of two behaviors observed during the motherinfant interaction. This method allows the user to assess intra- and interobserver differences and to examine the relationship between these differences and subject characteristics.
\end{abstract}

In the past few years, methods of collecting and analyzing observational data have received a great deal of attention (Deni, 1977; Gass, 1977; Lewis \& Lee-Painter, 1974; Sackett, 1978; Sidowski, 1977, pp. 403455; Stephenson, Smith, \& Roberts, 1976; Taerum, Ferris, Lytton, \& Zwirner, 1976). However, very few investigators have attended to an equally important issue-the reliability of observational data. The most commonly reported measure of "reliability" is the interobserver agreement percentage, which is simply: [(agreements)/(agreements + disagreements)] $\times 100$. This approach, although widely used, provides an estimate of reliability that may be quite misleading (Berk, 1979; Hollenbeck, 1978; Johnson \& Bolstad, 1973; Mitchell, 1979).

One problem with the interobserver agreement percentage is that it does not account for the degree of agreement between observers; that is, it is calculated on an all-or-none basis. This is particularly a problem when the data have been collected in "real-time," because the probability of two observers agreeing exactly on both the onset and offset of a behavior is fairly small. A second problem is that the interobserver agreement percentage does not account for the probability of chance agreement, which varies according to the rate of occurrence of the behavior. A third problem is that the interobserver agreement percentage does not relate the magnitude of observer disagreement to the magnitude

This research was supported by PHS National Research Service Award 1 F32 HD05375-02 (NICHHD), the Johnson \& Johnson Baby Products Company, and PHS National Research Service Award 5 T32 NU07004-02 (Division of Nursing, Health Resources Administration). This report was presented by the first author at the 1979 meetings of the Society for Research in Child Development. We would like to thank Richard A. Holm and Norma L. Dermond for their assistance. Requests for reprints should be sent to Cathryn L. Booth, Child Development and Mental Retardation Center, WJ-10, University of Washington, Seattle, Washington 98195 . of other sources of error; that is, it attributes variance only to observer differences.

Alternatives to the use of the interobserver agreement percentage in observational research have recently been reviewed by Berk (1979) and Mitchell (1979). One option is to use one of the interobserver agreement indices, such as Cohen's Kappa, that control for chance agreement between observers. These indices (see Berk, 1979, for a complete listing) are better than the interobserver agreement percentage, but the fact remains that all of them describe only the behavior of the observers, rather than the consistency or stability of the behavior of the subjects.

Another alternative is to use traditional reliability estimates. This approach does solve some of the problems of the observer agreement indices, but it is limited by the underlying assumption that the variance in a set of scores is attributable only to individual differences among subjects and to measurement error.

Another, more promising, alternative is the generalizability study (G-study) (Cronbach, Gleser, Nanda, \& Rajaratnam, 1972). The major advantage of a G-study is that it allows the variance in a set of scores to be partitioned among several sources (e.g., observers, occasions, subjects, error) rather than attributing it just to observers or just to subject differences and error. That is, a G-study enables the researcher to independently estimate and compare the variance attributable to several sources or "facets." A G-study also yields an intraclass correlation coefficient, or generalizability coefficient (G-coefficient), a more general version of the familiar reliability coefficient, which describes the overall quality (dependability) of the data. This procedure has been most often used with traditional psychometric tests, but it is applicable to observational data as well (Berk, 1979; Jones, Reid, \& Patterson, 1975; Leler, 1971; McGaw, Wardrop, \& Bunda, 1972; Mitchell, 1977). 
The purpose of this report is to demonstrate the practical application of generalizability theory to the assessment of the quality of observational data. More specifically, we will illustrate how a G-study can be used to assess (1) differences between observers, (2) changes within observers over time, and (3) the relationship between subject characteristics and observer reliability.

\section{DATA COLLECTION}

The subjects were 19 mothers and their 16-week-old infants who had participated in a study of infant massage. Ten of the mothers had been trained to massage their babies with baby powder, and nine had been trained to massage without baby powder. During a 16-week clinic visit, each mother was asked to massage and exercise her baby, as she normally would, in a home-like setting. The massage/exercise sessions were videotaped from an adjoining observation booth. The videotapes were then reviewed by two independent observers, using a real-time keyboard system (BOSS) to code-record ongoing behaviors. The frequency and duration of various massage and exercise strokes were recorded, as well as nonmassage activities such as caregiving, looking/talking, and touching. Approximately 2 months after the tapes were coded, the same observers coded all of the videotapes again. Thus, each observer coded all of the videotapes twice, for a total of 76 observations.

\section{DATA ANALYSIS AND RESULTS}

A series of two-facet (coders and occasions) G-studies were performed on the frequency and duration of two behaviors, "hands on" and "hands off." The former behavior refers to the times that the mother touched the baby when she was not specifically massaging or exercising; the latter behavior refers to the times the mother was not touching the baby. These behaviors occurred independently; that is, neither the frequencies nor the durations were significantly correlated $(r=.13$ and $\mathrm{r}=-.14$, respectively). The powder and nonpowder data were analyzed separately, resulting in a total of eight G-studies.

There are three basic steps involved in a G-study. First, a repeated-measures analysis of variance (ANOVA) is performed, using the G-study facets as factors. Second, the mean squares from the ANOVA are used to calculate variance components for each main effect and interaction. Finally, the variance components are used to calculate the G-coefficient, which, in this case, reflects the dependability of a subject's score generalized over coders and occasions.

In this study, a two-factor ANOVA was carried out with coders (two) and occasions (two) as within-subjects factors. The ANOVA summaries are given in Table 1. The following formulas (from Brennan, Note 1) were then used to estimate the variance components:

\begin{tabular}{lcc}
\multicolumn{1}{c}{ Source } & Estimate \\
Subjects (S) & $\hat{\sigma}_{\mathrm{S}}^{2} \quad$ & $\left(\mathrm{MS}_{\mathrm{S}}-\mathrm{MS}_{\mathrm{SC}}-\mathrm{MS}_{\mathrm{SO}}\right.$ \\
& $\left.+\mathrm{MS}_{\mathrm{SCO}}\right) / \mathrm{n}_{\mathrm{C}} \mathrm{n}_{\mathbf{O}}$
\end{tabular}

Occasions (O)

$$
\begin{aligned}
\hat{\sigma}_{\mathrm{O}}^{2}= & \left(\mathrm{MS}_{\mathrm{O}}-\mathrm{MS}_{\mathrm{SO}}-\mathrm{MS}_{\mathrm{CO}}\right. \\
& \left.+\mathrm{MS}_{\mathrm{SCO}}\right) / \mathrm{n}_{\mathrm{S}^{\mathrm{n}} \mathrm{C}}
\end{aligned}
$$

$S$ by $O$

Coders (C)

$$
\hat{\sigma}_{\mathrm{SO}}^{2}=\left(\mathrm{MS}_{\mathrm{SO}}-\mathrm{MS}_{\mathrm{SCO}}\right) / \mathrm{n}_{\mathrm{C}}
$$

$\hat{\sigma}_{\mathrm{C}}^{2} \quad=\left(\mathrm{MS}_{\mathrm{C}}-\mathrm{MS}_{\mathrm{SC}}-\mathrm{MS}_{\mathrm{CO}}\right.$

$\left.+\mathrm{MS}_{\mathrm{SCO}}\right) / \mathrm{n}_{\mathrm{S}} \mathrm{n}_{\mathrm{O}}$

S by C

C by $\mathrm{O}$

$\hat{\sigma}_{\mathrm{SC}}^{2} \quad=\left(\mathrm{MS}_{\mathrm{SC}}-\mathrm{MS}_{\mathrm{SCO}}\right) / \mathrm{n}_{\mathrm{O}}$

$\mathrm{S}$ by $\mathrm{C}$ by $\mathrm{O}$ (residual) $\quad \hat{\sigma}_{\mathrm{SCO}}^{2}=\mathrm{MS}_{\mathrm{SCO}}$

$\hat{\sigma}_{\mathrm{CO}}^{2}=\left(\mathrm{MS}_{\mathrm{CO}}-\mathrm{MS}_{\mathrm{SCO}}\right) / \mathrm{n}_{\mathrm{S}}$

where $\hat{\sigma}^{2}=$ estimated variance component, $M S=$ mean square, $\mathrm{n}_{\mathrm{S}}=$ number of subjects, $\mathrm{n}_{\mathrm{O}}=$ number of occasions, and $n_{C}=$ number of coders. (For alternative procedures appropriate when negative values are obtained for variance components, consult Cronbach et al., 1972, p. 57.)

Table 1

\begin{tabular}{|c|c|c|c|c|c|c|}
\hline \multirow[b]{2}{*}{ Source } & \multicolumn{3}{|c|}{ Powder $(n=10)$} & \multicolumn{3}{|c|}{ Nonpowder $(n=9)$} \\
\hline & $\mathrm{df}$ & MS & $\mathrm{F}$ & $\mathrm{df}$ & MS & $\mathbf{F}$ \\
\hline & \multicolumn{6}{|c|}{ Frequency of Hands On } \\
\hline$S$ & 9 & 111.12 & & 8 & 379.13 & \\
\hline 0 & 1 & 2.02 & .3 & 1 & .11 & .0 \\
\hline$S$ by $O$ & 9 & 7.52 & & 8 & 4.05 & \\
\hline C & 1 & 7.22 & .8 & 1 & 2.78 & .2 \\
\hline $\mathrm{S}$ by $\mathrm{C}$ & 9 & 9.28 & & 8 & 11.72 & \\
\hline $\mathrm{C}$ by $\mathrm{O}$ & 1 & 9.02 & 1.2 & 1 & 100.00 & $8.7 *$ \\
\hline \multirow[t]{2}{*}{$\mathrm{S}$ by $\mathrm{C}$ by $\mathrm{O}$} & 9 & 7.41 & & 8 & 11.44 & \\
\hline & \multicolumn{6}{|c|}{ Duration of Hands On } \\
\hline S & 9 & 19334.18 & & 8 & 13647.49 & \\
\hline 0 & 1 & 1.94 & .0 & 1 & 119.54 & .9 \\
\hline$S$ by $O$ & 9 & 210.79 & & 8 & 132.12 & \\
\hline $\mathrm{C}$ & 1 & 1327.10 & $7.9^{*}$ & 1 & 1388.80 & $7.0^{*}$ \\
\hline $\mathrm{S}$ by $\mathrm{C}$ & 9 & 168.54 & & 8 & 198.66 & \\
\hline$C$ by 0 & 1 & 494.21 & 2.9 & 1 & 603.52 & 2.8 \\
\hline \multirow[t]{2}{*}{$\mathrm{S}$ by $\mathrm{C}$ by $\mathrm{O}$} & 9 & 172.15 & & 8 & 214.11 & \\
\hline & \multicolumn{6}{|c|}{ Frequency of Hands Off } \\
\hline $\mathrm{s}$ & 9 & 42.27 & & 8 & 11.99 & \\
\hline 0 & 1 & 10.00 & $7.2^{*}$ & 1 & 4.00 & $6.4 *$ \\
\hline$S$ by $O$ & 9 & 1.39 & & 8 & .62 & \\
\hline $\mathrm{C}$ & 1 & 8.10 & 2.9 & 1 & 9.00 & 2.5 \\
\hline $\mathrm{S}$ by $\mathrm{C}$ & 9 & 2.82 & & 8 & 3.62 & \\
\hline $\mathrm{C}$ by $\mathrm{O}$ & 1 & .00 & .0 & 1 & 7.11 & $5.8^{*}$ \\
\hline \multirow[t]{2}{*}{$\mathrm{S}$ by $\mathrm{C}$ by $\mathrm{O}$} & 9 & .83 & & 8 & 1.24 & \\
\hline & \multicolumn{6}{|c|}{ Duration of Hands Off } \\
\hline $\mathrm{s}$ & 9 & 833.39 & & 8 & 281.50 & \\
\hline 0 & 1 & 33.67 & 1.1 & 1 & 39.06 & 1.9 \\
\hline$S$ by $O$ & 9 & 31.62 & & 8 & 20.48 & \\
\hline $\mathrm{C}$ & 1 & 216.69 & $10.5 * *$ & 1 & 89.93 & 1.1 \\
\hline $\mathrm{S}$ by $\mathrm{C}$ & 9 & 20.66 & & 8 & 80.83 & \\
\hline $\mathrm{C}$ by & 1 & 6.64 & .5 & 1 & 60.58 & 2.1 \\
\hline$S$ by $C$ by $O$ & 9 & 14.32 & & 8 & 29.03 & \\
\hline
\end{tabular}

ANOVA Summaries for the Frequency and Duration of Hands On and Hands Off

Note $-S=$ subjects, $O=$ occasions, $C=$ coders.

* $p<.05 . \quad * * p<.01$. 
The G-coefficients $\left(\xi \rho^{2}\right)$ were calculated in the following manner:

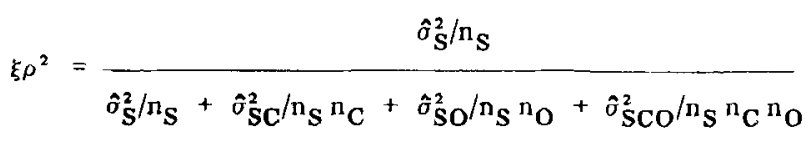

As shown in this formula, the G-coefficient expresses the proportion of variance in obtained scores attributable to individual differences, apart from the proportion of variance attributable to other sources-coders, occasions, and residual error. The variance components and G-coefficients for the present study appear in Table 2 .

For comparison purposes, interobserver agreement percentages were calculated for the total frequency and duration of each behavior, for each occasion. The following results were obtained by averaging the two occasions: frequency of hands on, $83 \%$; duration of hands on, $82 \%$; frequency of hands off, $70 \%$; duration of hands off, $69 \%$.

\section{DISCUSSION}

The G-study ANOVAs revealed significant differences between coders on several measures (duration of hands on for both groups and duration of hands off for the powder group). Two of the Coder by Occasion interactions were also significant (frequency of hands on and frequency of hands off for the nonpowder group), which would indicate that the coders changed in different directions from one coding session to the next or that one coder changed and one did not. For example, the mean frequency of hands off in the nonpowder group was 2.56 for one coder and .67 for the other coder for the first coding session. But for the second session the means were 2.33 and 2.22 , respectively. There were also two significant main effects of occasions (frequency of hands off in both groups), which, in this study, would indicate that the average of the scores assigned by both coders changed about the same amount in the same direction from the first session to the second session. (The occasions facet reflects mean observer changes over time rather than changes in subjects over time because the same videotapes were coded twice.)

These ANOVA results, by themselves, would cast doubts on the quality of the data gathered in this study. However, the variance components and G-coefficients lead to a quite different conclusion. In all of the analyses, individual differences (subjects) accounted for a large portion of the variance, whereas coders, occasions, and coders by occasions accounted for very little variance. Furthermore, the magnitude of the G-coefficients (.71 to .99) indicates that the subjects' scores were quite dependable across coders and occasions. Thus, the differences between coders and occasions were statistically significant but not important.

The G-studies also provided valuable information about the relative dependability of the powder and nonpowder data. For the frequency and duration of hands on, the G-coefficients were about the same for both groups. But for the frequency and duration of hands off, the coefficients were much larget in the powder group, which indicates that these subjects' scores were more consistent across coders and occasions than the nonpowder subjects' scores.

The difference between groups in the dependability of scores is also reflected in the powder group's larger variance components for subjects, which means that we would be able to predict the frequency and duration of hands off more accurately for a powder subject than for a nonpowder subject. This result makes sense because "hands off" was a built-in feature of the powder massage program. That is, the powder-group mothers were more predictable because their primary reason for taking their hands off the baby was to apply more powder to them. But the nonpowder mothers tended to take their hands off the baby for a variety of unpredictable reasons (e.g., spontaneous play, obtaining a toy or pacifier).

In summary, the $\mathrm{G}$-studies enabled us to determine that we had collected high-quality data on the frequency and duration of hands on and hands off and that these data were relatively uncontaminated by any intra. or interobserver differences. We also found out that the powder subjects were more "observable" in the sense

Table 2

Variance Components and G-Coefficients for the Frequency and Duration of Hands On and Hands Off

\begin{tabular}{|c|c|c|c|c|c|c|c|c|}
\hline \multirow[b]{3}{*}{ Source } & \multicolumn{4}{|c|}{ Hands On } & \multicolumn{4}{|c|}{ Hands Off } \\
\hline & \multicolumn{2}{|c|}{ Frequency Estimates } & \multicolumn{2}{|c|}{ Duration Estimates } & \multicolumn{2}{|c|}{ Frequency Estimates } & \multicolumn{2}{|c|}{ Duration Estimates } \\
\hline & Powder & Nonpowder & Powder & Nonpowder & Powder & Nonpowder & Powder & Nonpowder \\
\hline S & 25.43 & 93.70 & 4781.75 & 3382.70 & 9.72 & 2.24 & 198.86 & 52.30 \\
\hline 0 & 0 & 0 & 0 & 0 & .47 & 0 & .49 & 0 \\
\hline $\mathrm{S}$ by $\mathrm{O}$ & .06 & 0 & 19.32 & 0 & .28 & 0 & 8.65 & 0 \\
\hline C & 0 & 0 & 41.82 & 44.48 & .30 & 0 & 10.18 & 0 \\
\hline $\mathrm{S}$ by $\mathrm{C}$ & .93 & .14 & 0 & 0 & .99 & 1.19 & 3.17 & 25.90 \\
\hline $\mathrm{C}$ by $\mathrm{O}$ & .16 & 9.84 & 32.20 & 43.27 & 0 & .65 & 0 & 3.50 \\
\hline Residual & 7.41 & 11.44 & 172.15 & 214.11 & 83 & 1.24 & 14.32 & 29.03 \\
\hline G-Coefficient & .92 & .97 & .99 & .98 & .92 & .71 & .96 & .72 \\
\hline
\end{tabular}

Note $-S=$ subjects, $O=$ occasions, $C=$ coders $n_{S}=10$ (powder) or 9 (nonpowder), $n_{O}=2, n_{C}=2$. An entry of " 0 " indicates $a$ negative variance component, which was set equal to zero in the G-coefficient formula. 
that the frequency and duration of hands off were more predictable in this group than in the nonpowder group.

It is clear that the G-studies were much more valuable than the interobserver agreement percentages for gauging the dependability of the data in this study: The observer agreement method underestimated the quality of the data and provided information only about observer differences, but the G-studies allowed us to evaluate and compare all of the important sources of variance.

\section{OTHER DESIGNS}

There are many other two- and three-facet G-study designs that can be used to determine the quality of observational data. For example, a three-facet design could have been used in this study, with subjects nested in groups (powder, nonpowder) and crossed with coders and occasions. The advantage of this design is that it would have yielded a variance component for groups; the disadvantages are that the variance component for subjects would have been confounded by a Subject by Group interaction, and information about group differences in variance components and G-coefficients would have been lost.

The occasions facet can also be used in several other ways: To test the dependability of data over several different measurement occasions, each subject can be observed or taped more than once (rather than coding the same tapes twice). To test the dependability of data during a single observation session, the first and second halves or odd and even minutes of an observation can be regarded as "occasions."

The variance component and G-coefficient formulas for other common designs can be found in a technical report by Brennan (Note 1); a computer program for various two- and three-facet designs is also available (Erlich \& Shavelson, 1976).

\section{REFERENCE NOTE}

1. Brennan, R. L. Generalizability analyses: Principles and procedures (Tech. Rep. 26). Iowa City, Iowa: American College Testing Program, 1978.

\section{REFERENCES}

BERK, R. A. Generalizability of behavioral observations: A clarification of interobserver agreement and interobserver reliability. American Journal of Mental Deficiency, 1979, 83, 460-472.

Cronbach, L. J., Gleser, G. C., Nanda, H., \& Rajaratiam,
N. The dependability of behavioral measurements: Theory of generalizability for scores and profiles. New York: Wiley, 1972.

DEN1, R. BASIC-PLUS programs for Sackett's lag sequential analysis. Behavior Research Methods \& Instrumentation, 1977, 9. 383-384.

Erlich, O., \& Shavelson, R. Generalizability of measures: A computer program for two- and three-facet designs. Behavior Research Methods \& Instrumentation, 1976, 8, 407-408.

Gass, C. L. A digital encoder for field recording of behavioral, temporal, and spatial information in directly computeraccessible form. Behavior Research Methods \& Instrumentation, 1977, 9, 5-11.

Hollenbeck, A. R. Problems of reliability in observational research. In G. P. Sackett (Ed.), Observing behavior: Data collection and analysis methods (Vol. 2). Baltimore: University Park Press, 1978.

Johnson, S. M., \& Bolstad, O. D. Methodological issues in naturalistic observations: Some problems and solutions for field research. In L. A. Hamerlynck, L. C. Handy, \& E. J. Mash (Eds.), Behavior change: Methodology, concepts and practice. Champaign, Ill: Research Press, 1973.

Jones, R. R., Reid, J. B., \& Patterson, G. R. Naturalistic observation in clinical assessment. In P. McReynolds (Ed.), Advances in psychological assessment (Vol. 3). San Francisco: Jossey-Bass, 1975.

LELER, H. O. Mother-child interaction and language performance in young disadvantaged Negro children (Doctoral dissertation, Stanford University, 1970). Dissertation Abstracts International, 1971, 31, 4971B. (University Microfilms No. 71-2793)

Lewis, M., \& LeE-PAinter, S. An interactional approach to the mother-infant dyad. In M. Lewis \& L. A. Rosenblum (Eds.), The effect of the infant on its caregiver. New York: Wiley, 1974.

McGaw, B., Wardrop, J. L., \& Bunda, M. A. Classroom observational schemes: Where are the errors? American Educational Research Journal, 1972, 9, 13-27.

Mitchell, S. K. The reliability, generalizability, and interobserver agreement of data collected in observational studies (Doctoral dissertation, University of Washington, 1976). Dissertation Abstracts International, 1977, 37, 3583B. (University Microfilms No. 77-611)

Mitchell, S. K. The interobserver agreement, reliability, and generalizability of data collected in observational studies. Psychological Bulletin, 1979, 86, 376-390.

SAcketr, G. P. Observing behavior: Data collection and analysis methods (Vol. 2). Baltimore: University Park Press, 1978.

SIDowsKI, J. (Ed.). Behavior research methods \& instrumentation (Vol. 5). Austin, Tex: Psychonomic Society, 1977.

Stephenson, G. R., Smith, D. P. B., \& Robents, T. W. The SSR system: An open format event recording system with computerized transcription. Behavior Research Methods \& Instrumentation, 1976, 8, 259-277.

Taerum, T., Ferris, C., Lytton, H., \& Zwirner, W. Programs for the analysis of dependencies in parent-child interaction sequences. Behavior Research Methods \& Instrumentation, $1976,8,517-519$.

(Received for publication April 10, 1979; revision accepted August $9,1979$. ) 